\title{
University Experiment Research on the Development Based on Web of Experimental Teaching Platform
}

\author{
Zhigang Zhu ${ }^{\text {a }}$, Wei Sun ${ }^{b}$ \\ School of City Institute, Dalian University of Technology, Dalian Liaoning 116600, China \\ a mail: zhi_gang_zhu@126.coma, bjisuanjixiti@sina.com
}

Keywords: Web, experimental practice, teaching platform, development.

\begin{abstract}
The "network-based practice teaching resources platform" integrates practical teaching, management, and online self-directed learning. Its establishment has fundamentally changed the way of past practice teaching. Students can independently study experimental content and related resources, perform experimental tasks on their own, submit experimental reports and experimental results via the Internet on any networked computer. Teachers can check the experimental results submitted by students, correct experimental reports and generate experimental results on any networked computer, and realize the network of experimental reports; the interorganizational of experimental teaching management; the standardization of teachers' correction report.
\end{abstract}

\section{Introduction}

Practical teaching is an important part of talent cultivation, an important part of improving the quality of talent training, and it is also one of the important factors for measuring education and teaching quality. In order to meet the needs of universities in cultivating trans-century talents, further deepen the reform of practice teaching, promote the opening of laboratories, and strengthen the cultivation of practical and practical abilities of undergraduates. Practical teaching is an important link for higher education institutions to realize the goal of cultivating talents [1]. The overall quality of students and their cultivation of innovative awareness and innovative ability play a very important role. With the rapid development of higher education, with the increase in the number of students and the transformation of the demand for the talent market, the traditional practice teaching model has been severely impacted. How practical teaching adapts to this trend, and the construction of "network-based practical teaching resources platform" [2] has improved the college's practical teaching level. It has played a role in experimental teaching, experimental teaching management, and improving students' overall quality, scientific experiment ability, and training students' innovative ability. Important role [3].

\section{The Significance of the Construction of Web Experimental Teaching Platform for Colleges and Universities}

Web-based self-cooperation experimental teaching mode is mainly to train students' independent learning ability, collaboration ability, and innovative spirit. The experimental teaching management method should try to let students manage independently; the experiment time should be as open as possible; the experimental environment should try to adopt advanced Experimental facilities, with the aid of advanced technologies such as networking and multimedia; experimental teaching resources should build Web teaching websites; provide students with richer, more intuitive, experimental and experimental resources [4]; experimental organization methods are conducted in groups as a unit. dog. Students have created and set up an experimental teaching platform system that is conducive to cultivating innovative consciousness and practical ability, including basic experimental teaching platform, professional experimental teaching platform, project learning and innovation platform, instrument and equipment sharing platform, environmental technology safety platform, and experimental team construction platform. Teaching conditions guarantee platform, all-round service for student talents [5]. 


\section{Networked Practice Teaching Resources Platform Function}

"Networked Practice Teaching Resources Platform" integrates practice teaching, management, and online self-directed learning. It fundamentally changes the old experimental teaching mode where traditional practice teaching methods are single, time and place are fixed, learning materials and experimental content are limited. Through a wealth of online self-learning resources, experimental courseware, and the networking of experimental content, students are provided with more independent learning space in addition to classroom experiment teaching, and more extensive self-learning reference materials; students can independently learn experimental content and related Resources, autonomously complete experimental tasks, and submit experimental reports and experimental results via the Internet [6]. Teachers access the experimental results submitted by students through the Internet, correcting experimental reports and generating experimental results, and interacting with students through the platform. The network of experimental reports, the intelligentsia of experimental teaching management, the standardization of teacher correction reports, and the autonomy of students in completing experimental tasks have been achieved [7].

\subsection{Integrated Module Management Functions}

The integrated module first puts forward the general idea of integrated practical teaching, establishes practical teaching methods that meet the student's cognitive laws, and systematically arranges all aspects of practical teaching, from shallow to deep, from simple to complex, from verification to application, and from singleness to Comprehensive, from general to innovation, through the practice of progressive teaching layers, to form an integrated theory of practical teaching system. Based on the objective teaching system of practice, we integrate knowledge, skills and quality into a whole. The practical teaching process is divided into classroom teaching practice, simulated practical teaching [8], comprehensive practical teaching, on-campus practical training, off-campus internship, comprehensive internship, and graduation design. Taking employment as the orientation and comprehensive professional competence as the main line, the overall design of each practical teaching link will be carried out[9].

\subsection{Teaching Resources Management Function}

Through the teaching resource module, teachers use this platform to provide students with materials and materials, including the curriculum syllabus, experimental outline and teaching plan, teaching courseware, video, simulation software, etc. After the students download, they understand the nature of the courses, the experimental items, and Arrange, preview, prepare the experiment in advance, simulate the effect of the experiment by simulation software, identify the problem, consider the solution, and facilitate communication with the teacher or classmate in the experiment class.

\subsection{Job Management Function}

In order to enable students to effectively consolidate the knowledge taught by teachers in the classroom and to facilitate the teacher's understanding of the students' learning situation, students are required to do the corresponding exercises in class time. The teacher publishes the job to the Internet through this platform and records the job by setting the corresponding status flag. The student downloads it by himself. After completing the job, he/she indicates his/her basic information and submits the job to the website. After the teacher makes the correction, he/she makes a correction. Opinions, students can browse the teacher's feedback after logging in again. The teacher records each assignment submitted by the student as a reference to the usual grades and provides a reliable basis for the final grade.

\subsection{Course Experiment Management Function}

Curriculum experiment is an important part of computer science teaching. Through personal practice, students can deepen their understanding of knowledge, and can also improve their own practical ability and comprehensive application ability in a simulated experimental environment. Teachers publish experimental projects and arrangements for a course during the semester to the Internet. Students can download and view their situation in advance. The experiment can be fully prepared according to the progress of the course and experimental arrangements, which can also 
improve the efficiency of practical lessons. At the end of the experiment, the students submit this experiment report, and the teacher records the experimental results.

\subsection{Course Design and Graduation Design Management Functions}

Curriculum design is a practical lesson for a certain course. Teachers send the contents and requirements of the course design to the Internet. Students can apply the knowledge learned to practice and use the tools they learn to develop a set of small software (or Combine software and hardware to solve practical problems and summarize the design process and roll through design reports. According to the design and completion of the student's soft (hard) items, the writing of the report, and the answer to the teacher's question, the teacher will finally give the results of the course design.

Graduation design is an important practical teaching link for cultivating students' comprehensive quality and practical ability. The instructor guides the graduates on the Internet to the various tasks of graduation design and realizes online information processing on many aspects of graduation design, providing a new method for the management of graduation design (thesis). Students take full advantage of their expertise, select the appropriate topics and development tools and environment, complete the software and hardware design of the topic and write reports and papers. According to the written situation of the students' documents, software operation, hardware design, thesis writing, and defense, etc., the graduation design (thesis) of the students is given.

\subsection{Teacher and Student Interaction Management Functions}

The system provides a platform for interaction between teachers and students and between students and students. Each day, one or more teachers answer questions online. Students may encounter problems or confusion in their learning. Provides timely coaching and does not require a workplace.

\subsection{Remote Experiment Function}

The remote lab is an experimental network that simulates the actual network environment. It serves as an application platform for cohesion theory and practice and provides a real environment and operation meeting for the practical teaching courses in colleges and universities. The remote lab consists of remote preview experiments, remote booking experiments, remote operation experiments, remote teaching management, remote job management, and remote operation monitoring. The laboratory's orientation aims at students of network professional courses, aiming to improve students' knowledge, skills, management, and practical skills in networking; they can develop students into professional network skills, and can directly carry out network design, installation, and debugging. Technical talents. The network laboratory aims to create high-quality and practical network technology talents and give full play to their maximum potential.

\subsection{Teaching Evaluation Function}

A complete set of practical teaching evaluation system is crucial for the improvement of teaching quality and the cultivation of applied talents. First of all, through investigation and analysis, combined with the actual situation of the school's practical teaching, determine the reasonable evaluation factors, try to exclude the impact of human factors, students prepare lessons for the experimental teacher, explain, experiment class counseling, homework correction, the use and maintenance of experimental equipment, experiment content Timely arrangements and other conditions to evaluate, while also requiring students to put forward suggestions for improvement, will help improve the quality of practical teaching. Secondly, based on the performance and achievements of the students in all aspects of integrated practical teaching, the teacher will make an overall assessment and give students guidance to provide a reliable reference for the students to further improve their comprehensive ability. 


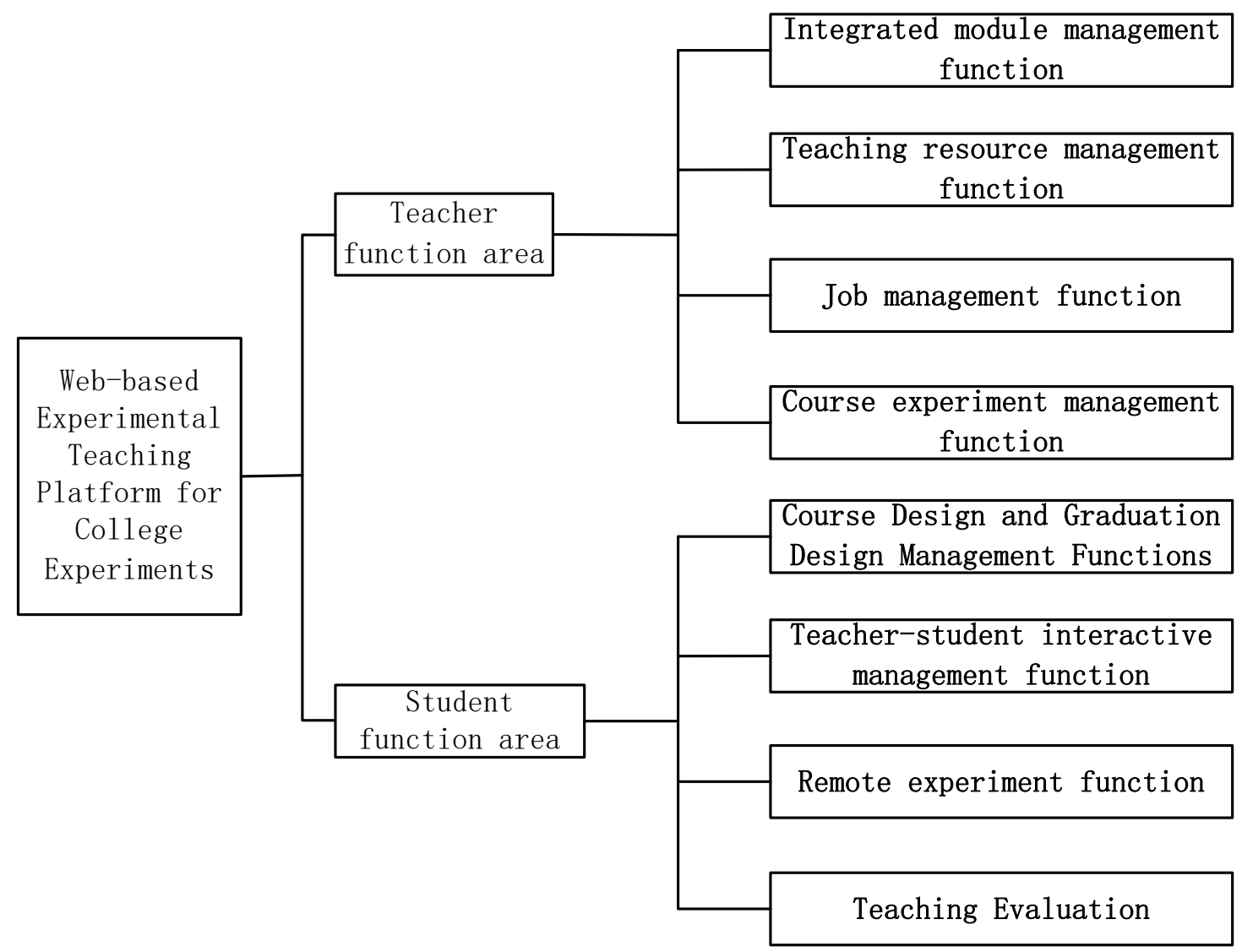

Fig. 1. Web-based functional modules of experimental teaching platform for colleges and universities

\section{System Implementation Technology}

The web server operating system of the experiment management system adopts Linux. Linux has excellent features in many aspects. The Web service container uses the Apache+Tomcat collaboration server architecture. Apache is responsible for the distribution of static content as a server, and Tomcat acts as a Web application server to handle dynamic requests behind the scenes. In order to improve the utilization efficiency of servers and other resources, the server adopts a Dispatcher-based Web server cluster [4].

\subsection{Development Technology Architecture}

The system development framework uses the Struts+Spring+Hibernate composite framework under the JEE framework. It has a three-tier structure and is divided into a presentation layer, a business logic layer, and a persistence layer. The presentation layer adopts the traditional JSP technology and adopts the MVC structure of Struts to control the interaction between the business logic layer and the presentation layer and invokes the Service component of the business logic layer. The business logic layer is responsible for implementing the business logic and is based on the DAO layer. The positive mode package of the DAO component completes the business logic required by the system. The persistence layer is responsible for interacting with the persistent object. This layer encapsulates the operation of adding, deleting, checking, and modifying data.

\subsection{Automatic Correction Implementation Technology}

The automatic correction system to be implemented in the system will introduce an expert system based on the rules engine to improve the intelligence of automatic correction. By separating the data, knowledge base, and program control, the rules based on the knowledge base will be independent of the computer program. The complexity of the automatic correction of subjective questions. The expert system is usually composed of several parts: human-computer interaction interface, knowledge base, interpreter, integrated database, blackboard, and inference engine. 


\section{Web-Based Experimental Teaching Platform for Colleges and Universities}

Web-based platform has played an important role in cultivating students' hands-on practical ability, scientific research ability, and scientific and technological innovation ability. In experimental teaching, students can choose to study in advance according to their own learning level, progress, and time, according to the requirements of the online experiment instruction book. Content, in order to achieve the teaching concept of teaching students in accordance with their aptitude, so that each student can receive experimental guidance in line with their own characteristics, realize multiple levels of gradient-graded experimental teaching, implement hierarchical teaching methods, carry out teaching according to their aptitude, and give full play to the initiative of the student body. And creativity, which promotes the development and growth of individual talents, guarantees the efficient operation of experimental teaching, and enables teaching resources to be shared to the maximum extent; not only improves the students' practical ability, but also the ability of independent learning, independent analysis, and problem solving. It broadens students' computer knowledge; improves the efficiency of experimental courses, truly provides an environmental platform for open experimental teaching, and provides a guarantee platform for experimental teaching reforms. Through this platform, students' learning locations and learning time Become Flexible, open learning styles that enable independent learning and communication. In the past, students' learning must be conducted at a fixed location and at a fixed time. With this comprehensive teaching management platform, students' learning time and place become relatively flexible. Students can access the Internet as long as they can access the Internet. The management platform conducts learning to achieve "individual education" that traditional education cannot achieve.

\section{Conclusion}

With the rapid development of science and technology, the country's requirements for quality of talents are getting higher and higher. Our school is also facing the challenge of accelerating the implementation of the "Building a world-class university". The task of cultivating innovative talents is getting heavier. Web-based self-cooperation experimental teaching mode utilizes network technology and platform to provide an active and open teaching environment for self-directed experimental teaching. Teachers can continuously guide students to think independently and learn independently through teaching resource reorganization. The effect has been fully recognized in practice teaching. We will work harder to continue to deepen experimental and practical teaching reforms and make greater contributions to fostering more future-oriented engineering leaders and top-notch innovative talents.

\section{References}

[1]. Wu Jianqiang, Li Yu, Qi Fengyan, et al. Fully open, self-learning model, experimental teaching, exploration, nuclear exploration. Chinese University Teaching, Vol. 2 (2011) No.9, p.70-72.

[2]. Xu Jiarui, Zhou Qin, Chen Buyun, et al. The exploration and practice of constructing innovative experiment systems. Experimental Technology and Management, Vol. 25 (2012) No. 9, p.1-4.

[3]. Zheng Jiamao, et al. Build an innovative experimental platform combining "doing research and research" to promote students to "do high school, study in China, research, create in research". Experimental Technology and Management, Vol. 18 (2013) No. 12, p.1-4.

[4]. Yan Wei, Yuan Yunsong, et al. Strengthening laboratory openness to provide good support for the cultivation of innovative people. Laboratory Research and Exploration, Vol. 28 (2015) No. 5, p.16-17.

[5]. Chen Bin, Zhang Xiaohua, et al. Open Experiment Teaching Practice. Laboratory Research and Exploration, Vol. 15 (2005) No. 7, p.110-113. 
[6]. Wang Xingbang, et al. Seriously sum up, improve the concept, concise the results, highlight the characteristics, meet the acceptance of the National Experimental Teaching Demonstration Center. Experimental Technology and Management, Vol. 12 (2007) No. 6, p.1-5.

[7]. Shen Xiaoxiong, Han Lian, et al. Taking the reform of the experimental teaching content system as a leader, comprehensively improving the quality of experimental teaching. China Higher Education Research, Vol. 31 (2012) No. 13, p.78-79.

[8]. Li Ye, et al. The feasibility study of the independent design of mechanical experimental teaching in colleges and universities. Journal of Zhongzhou University, Vol. 15 (2012) No. 7, p.90-91.

[9]. Huang Yuquan, et al. Developing Experimental Courses and Teaching: A New Approach to Teacher Education Reform. Educational Development Research, Vol. 9 (2009) No.5, p.49-53 